\title{
Association between apparent temperature and acute coronary syndrome admission in Rasht, Iran
}

\author{
Mohammad Taghi Moghadamnia, ${ }^{1}$ Ali Ardalan, ${ }^{1}$ Alireza Mesdaghinia, ${ }^{2}$ \\ Kazem Naddafi, ${ }^{2}$ Mir Saeed Yekaninejad ${ }^{3}$
}

'Department of Disaster Public Health, School of Public Health Tehran University of Medical Science, Tehran, Iran

'Department of Environmental Health Engineering, School of Public Health, Tehran University of Medical Sciences; Institute for Environment Research, Tehran, Iran

${ }^{3}$ Department of Epidemiology and Biostatistics, School of Public Health, Tehran University of Medical Sciences, Tehran, Iran

\section{Correspondence to} Professor Ali Ardalan, Department of Disaster Public Health, School of Public Health, Tehran University of Medical Sciences, Tehran, Iran; aardalan@tums.ac.ir

Received 17 May 2018

Revised 13 August 2018

Accepted 13 September 2018

Check for updates

(c) Author(s) (or their employer(s)) 2018. No commercial re-use. See rights and permissions. Published by BMJ.

To cite: Moghadamnia MT Ardalan A, Mesdaghinia A, et al. Heart Asia

2018:10:e011068

doi:10.1136/

heartasia-2018-011068
ABSTRACT

Objective Our objective was to assess the relations between apparent temperature and incidence of acute coronary syndrome (ACS) in Rasht, Iran.

Methods We used a time-series analysis to investigate the relationship between apparent temperature and hospital admission from 2005 to 2014. Distributed lag non-linear models were used to estimate the association between ACS hospitalisation and apparent temperature. To examine the high-temperature effect on ACS hospital admission, the relative risk of ACS hospital admission associated with high temperature, the 99th percentile of temperature $\left(34.7^{\circ} \mathrm{C}\right)$ compared with the 75 th percentile of temperature $\left(26.9^{\circ} \mathrm{C}\right)$, was calculated. To assess the cold effect on ACS hospital admission, the relative risk of ACS hospital admission associated with cold temperature, the first percentile of temperature $\left(-0.2^{\circ} \mathrm{C}\right)$ compared with the 25 th percentile of temperature $\left(8.2^{\circ} \mathrm{C}\right)$, was evaluated.

Results The cumulative effect of hot exposure on ACS admissions was statistically significant, with a relative risk of 2.04 (95\% Cl 1.06 to 4.16). The cumulative effect of cold temperature on ACS admissions was found to be non-significant. The highest risk of ACS admission in women was in $38^{\circ} \mathrm{C}(\mathrm{RR}, 2.03,95 \% \mathrm{Cl} 1.04$ to 4.18$)$. The effect of hot temperature on ACS admission occurred immediately (lag 0) (RR, 1.09, 95\% Cl 1.001 to 1.19).

Conclusions The high apparent temperature is correlated with a higher ACS admission especially on the same day. These findings may have implications for developing intervention strategies to reduce and prevent temperature-related morbidity especially in the elderly.

\section{INTRODUCTION}

Climate change is an issue of great importance for public health. ${ }^{1}$ Climate change affects all sections of the community and influences human health by direct and indirect pathways. The four key sectors that will be affected by climate change are water, food, settlement and health. The heat-related mortality is the most direct health impact of global warming. ${ }^{2}$ Although well-studied investigations about the effect of hot temperature on acute coronary syndrome (ACS) in developed countries have been conducted, ${ }^{3}$ there is a paucity of research on this problem in low-income and middle-income countries such as Iran. ${ }^{4}$ An Extreme event weather, such as heatwaves and cold spells, is associated with increased cardiovascular diseases (CVDs), respiratory diseases and renal diseases, leading to mortality and morbidity. ${ }^{5}$ Ambient temperatures, including minimum, maximum and mean temperatures, are used to assess the impact of temperature on health. ${ }^{6}$
ACS is one of the most common causes of death in patients with CVD characterised by an acute onset of myocardial ischaemia resulting in myocardial death. ${ }^{7}$ The spectrum of ACS includes unstable angina, non-ST-segment elevation myocardial infarction (NSTEMI) and ST-segment elevation myocardial infarction (STEMI). ${ }^{8}$ There are few studies about which particular cardiovascular disorders are most influenced by hot and cold spells. ${ }^{9}$ Increases in hospital admissions of ACS during extreme heat are mostly attributed to hyperthermia, dehydration, heat stroke, ischaemic stroke, diabetes, and fluid and electrolyte imbalances. ${ }^{10}$ Several possible physiological changes have been proposed to explain the seasonal variation of ACS incidence, including changes in clotting mechanisms, lipid levels, and blood pressure which is associated with physiological changes like increased plasma viscosity. ${ }^{11}$

The significant relationship between temperatures and ACS incidence suggests that cold temperature may play an important role in the incidence of ACS. ${ }^{12}$ Previous studies reported that exposure to cold weather would be increased in temperature-related mortality from coronary artery disease. ${ }^{13}$ Cold temperature causes vasoconstriction, which increases blood pressure and the risk of cardiovascular events. Exposure to cold and hot temperatures puts stress on the cardiovascular system, especially in vulnerable people such as the elderly, and increases the risk of ACS. ${ }^{14}$

There has been a significant increase in the incidence of coronary artery diseases in Iran in recent years. ${ }^{15}$ The high incidence of coronary artery disease (CAD) and associated morbidity and mortality in Iran is one of the most concerning public health issues. In Iran, the prevalence of coronary artery disease is higher than Western countries, and there is limited information in regard to coronary risk factors in Iran. ${ }^{15}$ Due to the lack of studies, the association between metrological variables and incidence of CVD has not been well evaluated in the Iranian population. Our objective was to assess the relationship between apparent temperature and incidence of ACS using time-series analyses.

\section{METHODS}

This study was conducted in Rasht, the centre of the Guilan province, which is the biggest city located in the north of Iran. This city has a humid subtropical climate with relatively high temperatures in summer and mild winters and occasional winter storm with rainfall coming from convectional thunderstorm activity. The municipality has an area of $180 \mathrm{~km}^{2}$ 


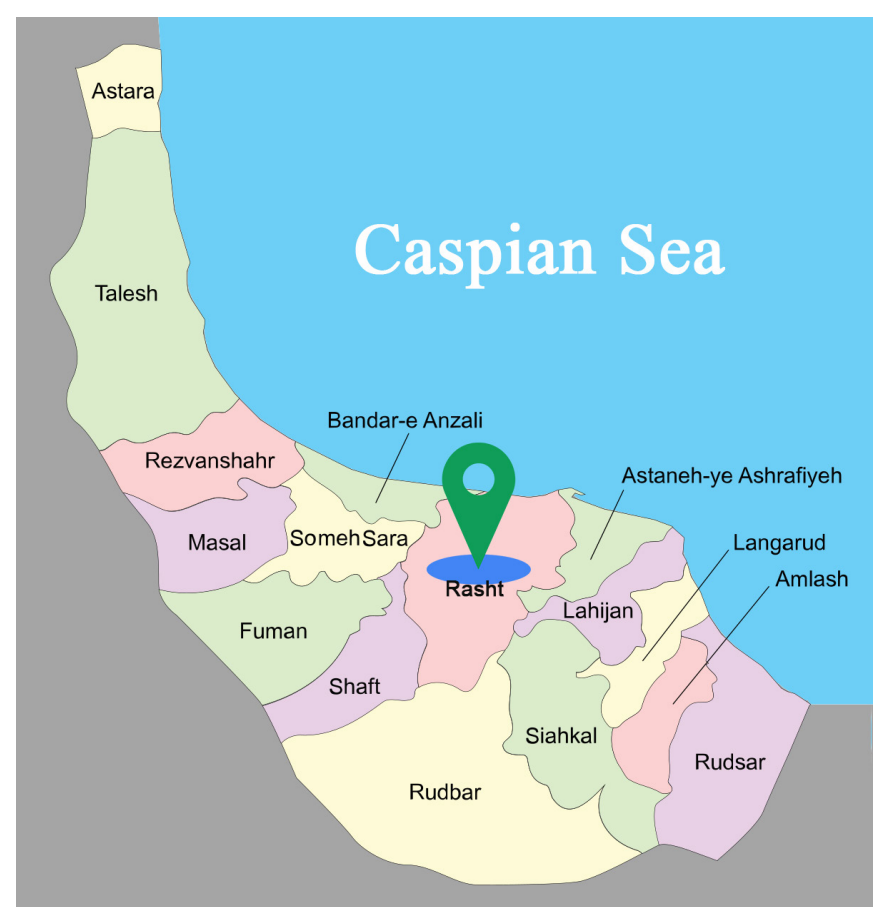

Figure 1 The map of Rasht city.

with more than one million people (Census 2016) at $37.2682^{\circ}$ latitude and $49.5891^{\circ}$ longitude (figure 1$)$.

\section{Hospital admission data}

Data on the daily counts of admissions for ACS such as unstable angina pectoris (UAP), STEMI and NSTEMI were obtained from the only cardiovascular hospital in Rasht during the period 2005-2014. There is one specialised cardiovascular hospital in Guilan province named Dr Heshmat, Medical and Research Centre. We selected patients with ACS according to the International Classification of Diseases V.10 (I20.0, UAP; I21.0-I21.9, STEMI and NSTEMI).

\section{Meteorological data}

The daily data of weather conditions included the minimum $\left({ }^{\circ} \mathrm{C}\right)$, maximum $\left({ }^{\circ} \mathrm{C}\right)$ and mean of temperature $\left({ }^{\circ} \mathrm{C}\right)$, dew point $\left({ }^{\circ} \mathrm{C}\right)$, barometric pressure (mbar), humidity (\%), and speed of the wind $(\mathrm{m} / \mathrm{s})$ over the 10 -year period gathered from the Rasht meteorological centre.

We recruited apparent temperature as exposure variable that combined heat and high humidity, which is a composite index of human discomfort. This index characterises the physiological

\begin{tabular}{|c|c|c|c|c|c|c|c|}
\hline Metrological variables & Min & $25 \%$ & $50 \%$ & Mean & $75 \%$ & Max & SD \\
\hline Apparent temperature $\left({ }^{\circ} \mathrm{C}\right)$ & -2.585 & 8.174 & 17.49 & 17.38 & 26.69 & 38.57 & 9.98 \\
\hline Ambient temperature $\left({ }^{\circ} \mathrm{C}\right)$ & 0 & 10 & 17.4 & 16.83 & 23.7 & 32.05 & 7.51 \\
\hline Humidity (\%) & 16 & 77.75 & 84.38 & 82.99 & 89.88 & 100 & 9.83 \\
\hline Dew point $\left({ }^{\circ} \mathrm{C}\right)$ & -8.175 & 7.275 & 13.42 & 13.06 & 19.3 & 25.51 & 6.74 \\
\hline Wind speed $(\mathrm{m} / \mathrm{s})$ & 0 & 1.125 & 1.5 & 1.687 & 2 & 8.375 & 0.87 \\
\hline Myocardial infarction & 1 & 3 & 5 & 5.75 & 7 & 11 & 2.24 \\
\hline Female & 1 & 2 & 4 & 4.42 & 6 & 9 & 2.02 \\
\hline Male & 1 & 3 & 5 & 6.23 & 8 & 12 & 2.31 \\
\hline Age $<65$ & 1 & 3 & 5 & 5.12 & 5 & 10 & 1.98 \\
\hline Age $\geq 65$ & 1 & 4 & 6 & 5.96 & 8 & 12 & 2.40 \\
\hline
\end{tabular}

experience better than ambient temperature because it captures the physiological experience better than temperature alone and also has been used in other studies assessing morbidity and mortality. ${ }^{16}{ }^{17}$ With the increase in dew points, the apparent temperature exceeds the actual temperature and the increase in physiological heat stress. The apparent temperature (AT) was calculated with the following formula:

$\mathrm{AT}=-2.653+(0.994 \times \mathrm{Ta})+\left(0.0153 \times \mathrm{Td}^{2}\right)^{16}$

where $\mathrm{Ta}$ is air temperature and $\mathrm{Td}$ is dew point temperature.

\section{Data analysis}

We used a time-series regression to investigate the relationship between apparent temperature and hospital admission. Previous studies have reported that the association between temperature and mortality is non-linear and might be delayed in time. ${ }^{18}$ The risk of hospitalisation will be increased on the same day and on several following days. ${ }^{14} 19$ All data analyses were performed using the R V.3.3.3 software. The 'dlnm' package was used to fit the distributed lag non-linear model (DLNM). Spearman's correlation coefficients were used to explore the monotonic relation between daily admissions of patients with ACS and apparent temperatures. DLNMs were used to estimate the association between ACS hospitalisation and lags of apparent temperature, adjusted for time trends using natural cubic splines, the day of the week and holidays with the R package dlnm. To assess possible delayed associations, we examined the impact of apparent temperature up to 20 days before the admissions. ${ }^{20} 21$ A quasi-Poisson regression model combined with a DLNM was used to assess the impact of daily apparent temperature on admission at different lag days. This matrix is obtained by the combination of the exposure-response function with a natural cubic spline with three internal knots placed at the 10th, 75 th and 90th percentiles of city-specific apparent temperature distributions, and the lag-response function modelled with a natural cubic spline with three internal knots placed at equally spaced values in the log scale. ${ }^{19}$

The effects of high temperature on ACS admission for each $1^{\circ} \mathrm{C}$ increase in temperature from the 75 th $\left(26.9^{\circ} \mathrm{C}\right)$, 90th $\left(30.8^{\circ} \mathrm{C}\right)$, 95 th $\left(32.5^{\circ} \mathrm{C}\right)$ and the 99 th $\left(34.7^{\circ} \mathrm{C}\right)$ percentiles generally and also based on age and gender were investigated. Also the effects of low temperature on ACS admission for $1^{\circ} \mathrm{C}$ decrease from the 25 th $\left(8.2^{\circ} \mathrm{C}\right), 10$ th $\left(4.7^{\circ} \mathrm{C}\right), 5$ th $\left(2.6^{\circ} \mathrm{C}\right)$ and the 1 st $\left(-0.2^{\circ} \mathrm{C}\right)$ percentiles generally and based on age and sex were evaluated. ${ }^{22}$

To examine the high-temperature effect on ACS hospital admission overall and based on age and sex, the relative risk of ACS hospital admission associated with high temperature, the 99th percentile of temperature $\left(34.7^{\circ} \mathrm{C}\right)$ compared with the 75 th percentile of temperature $\left(26.9^{\circ} \mathrm{C}\right)$, was calculated. To examine the cold effect on ACS hospital admission overall and based on age and sex, the relative risk of ACS hospital admission associated with cold temperature, the first percentile of temperature $\left(-0.2^{\circ} \mathrm{C}\right)$ compared with the 25 th percentile of temperature $\left(8.2^{\circ} \mathrm{C}\right)$, was evaluated. ${ }^{23}$ We used the mean apparent temperature in the present study.

Sensitivity analysis was performed to test the robustness of our main results by changing the location of knots for exposureresponse, and 5-20 lag days for apparent temperature, 6-10 df for time trend, 3-10 df for relative humidity and atmospheric pressure were used, respectively.

\section{RESULTS}

The results of the DLNM model are provided linking climatological data with the daily incidence of ACS for the total population, 


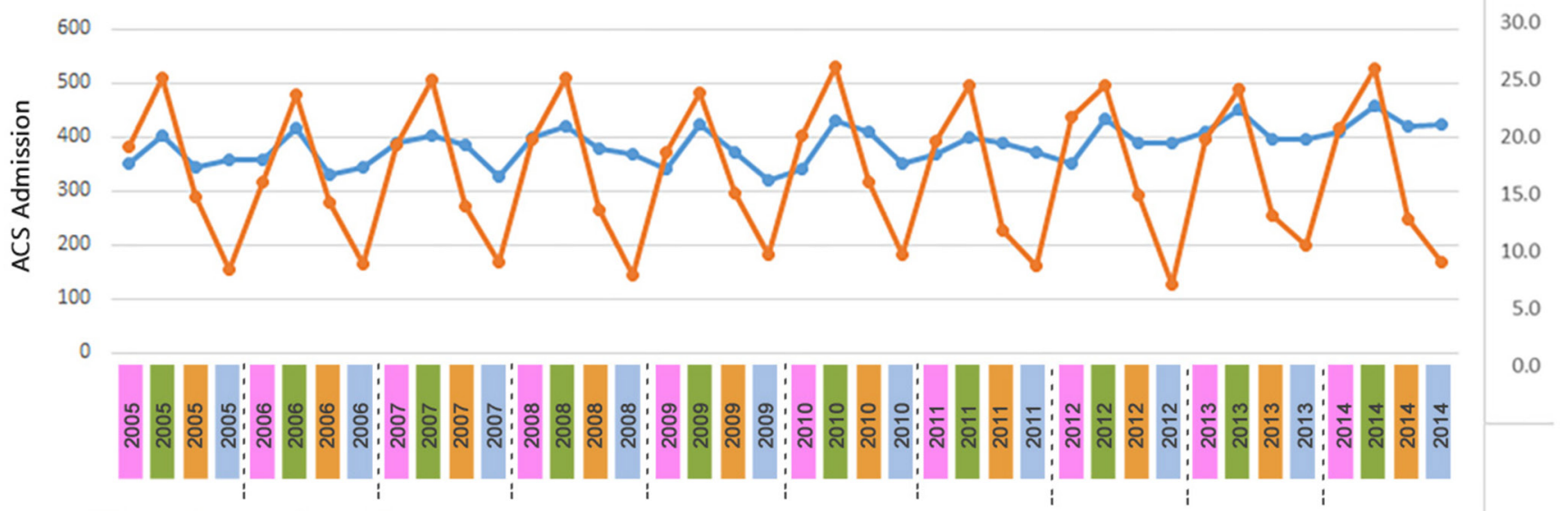

S pring Summer A utumn W inter

$\multimap$ ACS cases $\longrightarrow$ Main Apparent Temperature

Figure 2 Time-series plot of acute coronary syndrome (ACS) admission and apparent temperature.

men, women and subjects under and over 65 years of age. In the 3653-day period from 20 March 2005 to 20 March 2015, there were 15094 ACS admissions, among them 2893 cases with UAP and 12201 with myocardial infarction. The mean daily ACS admission was $5.38 \pm 3.9$, and the average daily apparent temperature was $17.38^{\circ} \mathrm{C} \pm 9.98^{\circ} \mathrm{C}$ (table 1 ). The time-series plot of ACS admission and apparent temperature showed the seasonal variation of exposure and response outcome in 10 years of study, with high admission in summer (figure 2).

In figure 2 , the left graphs show the percentage change of ACS admission for each $1^{\circ} \mathrm{C}$ temperature drop in the 25 th $\left(8.2^{\circ} \mathrm{C}\right), 10$ th $\left(4.7^{\circ} \mathrm{C}\right), 5$ th $\left(2.6^{\circ} \mathrm{C}\right)$ and 1 st $\left(-0.2^{\circ} \mathrm{C}\right)$ percentiles of temperature overall and based on age and sex, respectively.

Our finding showed that with $1^{\circ} \mathrm{C}$ decrease in temperature in the $25 \mathrm{th}, 10 \mathrm{th}, 5 \mathrm{th}$ and $1 \mathrm{st}$ percentiles, the percentage of ACS admission decreased in all cases, men, women and people over 65 years, but increased in people under 65 years old.

In figure 3, the right graphs show the percentage change of ACS admission for each $1^{\circ} \mathrm{C}$ increase in temperature in the 75 th $\left(26.9^{\circ} \mathrm{C}\right)$, 90th $\left(30.8^{\circ} \mathrm{C}\right), 95$ th $\left(32.5^{\circ} \mathrm{C}\right)$ and 99 th $\left(34.7^{\circ} \mathrm{C}\right)$ percentiles of temperature overall and based on age and sex, respectively.

Figure 3 shows that changes in temperature from moderate (75th percentile) to hot (99th percentile) induced ACS admission increase in all cases, women and people under 65 years old.

The heat effect on ACS admission was significant, while the cold effect was not significant. The relative risk of heat exposure on ACS admissions was 2.04 (95\% CI 1.06 to 4.16) and for cold exposure was 0.87 (95\% CI 0.66 to 1.14 ), which was not significant (tables 2 and 3). The highest risk of ACS hospitalisation in women was in $38^{\circ} \mathrm{C}$ (RR, 2.03, 95\% CI 1.04 to 4.18$)$, but in men was non-significant in any temperature. The overall effect of heat and cold exposure on ACS admissions based on age was estimated and was not significant.

The distributed non-linear lag surface revealed exposure-lag response association with a non-linear relationship between apparent temperature and ACS admission, indicating higher admission risk at hot temperatures (figure 4). The graphs present the relative risk by lag 0-20 days in all cases, men, women, under 65 and over 65 years old.

Figure 5 shows the lag structures of apparent temperature effect over the same day up to 20 days before. Our findings showed immediate effects of hot temperatures on ACS admission, with the significant effects on the current day (lag 0 ).

The overall effect of hot temperature on ACS admission relative risk on the same day was 1.09 (95\% CI 1.001 to 1.19$), 1.11$
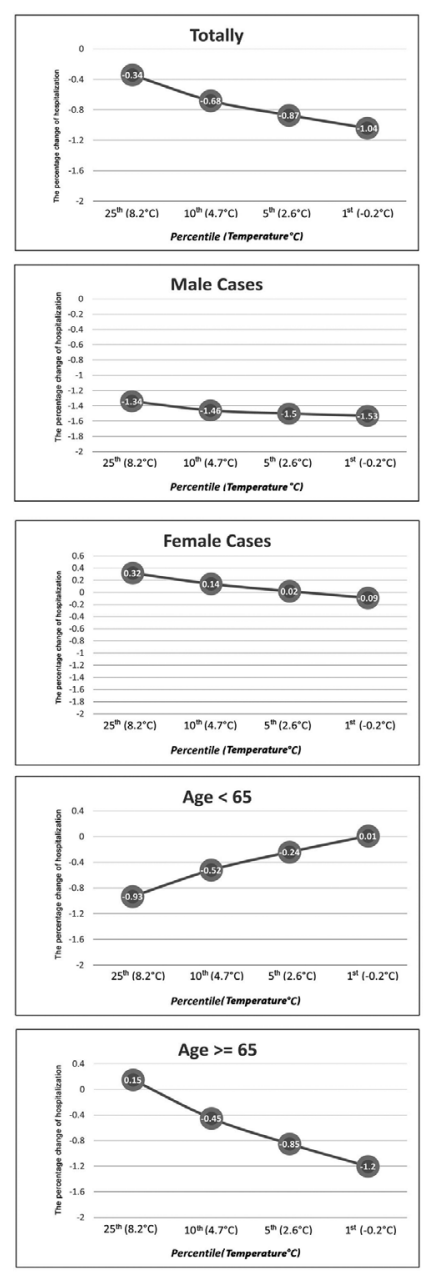

Cold Temperature
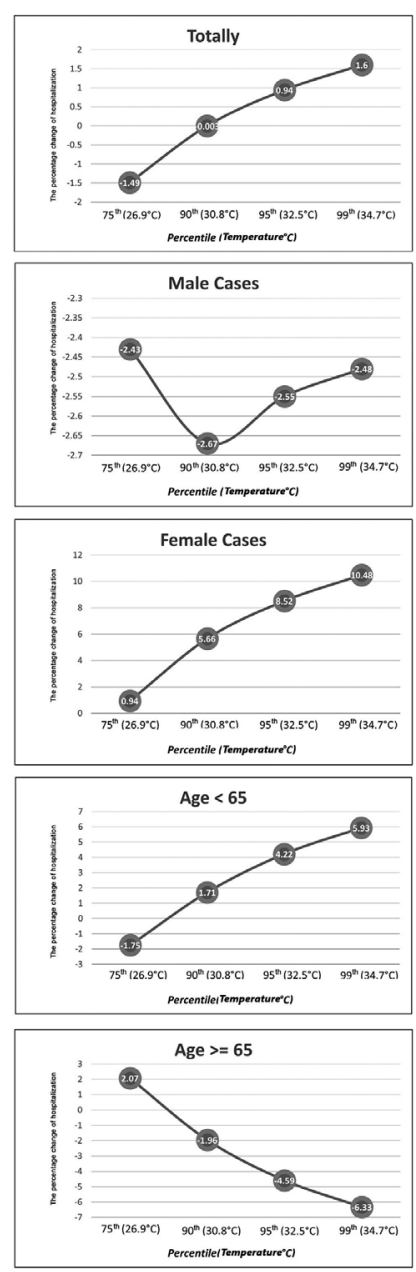

Hot Temperature

Figure 3 The percentage change of acute coronary syndrome admission related to temperature. 
Table 2 The cumulative effects of hot temperature on acute coronary syndrome with 99 th percentile of temperature $\left(34.7^{\circ} \mathrm{C}\right)$ compared with the 75th percentile of temperature $\left(26.9^{\circ} \mathrm{C}\right)$

\begin{tabular}{|c|c|c|c|c|c|}
\hline \multicolumn{6}{|c|}{ Relative risk $(95 \% \mathrm{CI})$} \\
\hline Lag & All cases & Male & Female & $\leq 64$ years & $\geq 65$ years \\
\hline 0 & 1.09 (1.02 to 1.19$)$ & 1.11 (0.96 to 1.28$)$ & 1.08 (1.02 to 1.23$)$ & 1.05 (0.94 to 1.17$)$ & 1.14 (1.01 to 1.28$)$ \\
\hline $0-1$ & $1.01(0.97$ to 1.06$)$ & $1.04(0.97$ to 1.12$)$ & $0.97(0.91$ to 1.04$)$ & 1.04 (0.98 to 1.10$)$ & 1.11 (1.01 to 1.23$)$ \\
\hline $0-2$ & 0.97 (0.93 to 1.03$)$ & $1.00(0.92$ to 1.09$)$ & 0.95 (0.88 to 1.02$)$ & 1.02 (0.95 to 1.08$)$ & 0.93 (0.87 to 1.02$)$ \\
\hline $0-3$ & $0.97(0.94$ to 0.9$)$ & $0.98(0.93$ to 1.02$)$ & $0.96(0.92$ to 1.00$)$ & 0.99 (0.96 to 1.03$)$ & $0.94(0.90$ to 0.97$)$ \\
\hline $0-7$ & $0.98(0.97$ to 1.00$)$ & 0.99 (0.96 to 1.02$)$ & $0.98(0.96$ to 1.01$)$ & $0.98(0.95$ to 1.01$)$ & $0.98(0.96$ to 1.01$)$ \\
\hline $0-14$ & $1.00(0.99$ to 1.012$)$ & $1.02(1.00$ to 1.04$)$ & $1.03(0.98$ to 1.02$)$ & $0.98(0.95$ to 1.01$)$ & 1.01 (0.98 to 1.03$)$ \\
\hline $0-20$ & $0.989(0.95$ to 1.02$)$ & 0.99 (0.94 to 1.04$)$ & $0.98(0.94$ to 1.02$)$ & $0.98(0.95$ to 1.02$)$ & $0.99(0.94$ to 1.03$)$ \\
\hline
\end{tabular}

(95\% CI 0.96 to 1.28$)$ and 1.08 (95\% CI 1.02 to 1.23$)$ in all cases, men and women, respectively (table 2).

Sensitivity analysis was performed in this study for modelling choices. The effect estimates of ACS admission due to temperature were similar when we changed the places of knots for temperature-admission relation and when 5-20 lag days for apparent temperature, 6-10 df for time trend and 3-10 df for relative humidity and air pressure were used, respectively.

\section{DISCUSSION}

This study examined the relationships between apparent temperature and ACS hospitalisation in Rasht, the centre of the Guilan province, in the northern part of Iran, between 2005 and 2014. This study indicated that the extremely hot temperatures increased the risk of ACS hospitalisation, but the cold temperature did not show any effect on ACS admission. This result is consistent with other investigations indicating hot weather is responsible for the most part of the temperature-related ACS admission. ${ }^{24}$ In contrast, a study reported the occurrence of acute myocardial infarction was associated with low temperatures, ${ }^{25}$ and the study conducted by Wolf et $a l^{3}$ showed that the risk for the occurrence of myocardial infarction was similar in winters and summers, which was non-significant. On the other hand, many previous studies showed both hot and cold temperatures increased the risk of ACS admission especially for myocardial infarction. ${ }^{14}$ One of the reasons for the contradiction in the results of our study and with other studies is the use of the apparent temperature index, which is a composite index of human discomfort due to combined heat and high humidity in this study. At higher humidity, the apparent temperature exceeds the ambient temperature and increases physiological heat stress. ${ }^{16}$ Moreover, exposure to high temperature could increase plasma viscosity, cholesterol levels in serum, changes in vascular tone, autonomic nervous system response, and ultimately increases the tendency to clot in the vessels. ${ }^{1126}$

In this study, the highest relative risk of ACS admission in all cases and women were $28^{\circ} \mathrm{C}$ and $38^{\circ} \mathrm{C}$, respectively. In this regard, Lee $e t a l^{27}$ reported a rapid increase of acute myocardial infarction (AMI) over $32^{\circ} \mathrm{C}$ and $29.6^{\circ} \mathrm{C}$, respectively. Our study showed seasonal variations in ACS admission so that the highest rate of admission was in summer. Consistent with this finding, Nastos et $a l^{24}$ in Crete Island, Greece, reported the same pattern. In contrast, many other studies reported that the occurrence of myocardial infarction is associated with the winter season. ${ }^{28}$

The difference between the results of this study and a number of previous studies ${ }^{26}$ could be due to the weather conditions of Rasht, with mild winters and hot and humid summers. The high humidity is known to increase risks because physiological responses for heat dispersion such as sweating are limited. ${ }^{29}$

This study has also explored the lag effects of temperature on ACS up to 20 days. The strongest relationship between high apparent temperature and ACS was on the same day, which is consistent with other studies. ${ }^{14}$ The effect of hot temperature on the elderly was immediate (lag $0-1$ ) but was delayed (lag $0-14)$ in men. According to previous studies, the temperature variability had delayed effect on health. ${ }^{18}$ The study conducted by Huang et $\mathrm{al}^{30}$ showed that the effect of the cold temperatures had a long lag period of 10-25 days, while hot temperatures had a short lag period of only 1-3 days. The ageing phenomena induces some physiological changes in thermoregulation and homeostasis, along with the prevalence of chronic conditions, which cause vulnerability to cold and heat. ${ }^{26}$

Considering global warming and the high air temperature in recent years in Iran, especially in northern Iran, policy makers, the local community and the public should strengthen awareness

Table 3 The cumulative effects of cold temperature on acute coronary syndrome with the first percentile of temperature $\left(-0.2^{\circ} \mathrm{C}\right)$ compared with the 25 th percentile of temperature $\left(8.2^{\circ} \mathrm{C}\right)$

\begin{tabular}{clllll}
\hline Relative risk $(95 \% \mathrm{Cl})$ & & & & & \\
\hline Lag & All cases & Male & Female & s64 years & $\geq 65$ years \\
\hline 0 & $1.03(0.96$ to 1.13$)$ & $1.11(0.96$ to 1.28$)$ & $0.98(0.96$ to 1.02$)$ & $1.05(0.94$ to 1.17$)$ & $1.01(0.98$ to 1.04$)$ \\
$0-1$ & $1.01(0.97$ to 1.06$)$ & $1.04(0.97$ to 1.12$)$ & $0.97(0.91$ to 1.04$)$ & $1.04(0.98$ to 1.10$)$ & $0.99(0.94$ to 1.04$)$ \\
$0-2$ & $0.97(0.93$ to 1.03$)$ & $1.00(0.92$ to 1.09$)$ & $0.95(0.89$ to 1.03$)$ & $1.02(0.96$ to1 1.08$)$ & $0.93(0.87$ to 1.02$)$ \\
$0-3$ & $0.99(0.96$ to 1.05$)$ & $0.98(0.93$ to 1.03$)$ & $0.96(0.92$ to 1.00$)$ & $0.99(0.96$ to 1.04$)$ & $0.94(0.90$ to 0.97$)$ \\
$0-7$ & $0.98(0.97$ to 1.00$)$ & $0.99(0.96$ to 1.02$)$ & $0.98(0.96$ to 1.01$)$ & $0.98(0.95$ to 1.01$)$ & $0.98(0.96$ to 1.02$)$ \\
$0-14$ & $1.00(0.99$ to 1.012$)$ & $1.02(1.00$ to 1.04$)$ & $1.03(0.98$ to 1.05$)$ & $0.99(0.96$ to 1.02$)$ & $1.01(0.98$ to 1.03$)$ \\
$0-20$ & $0.989(0.95$ to 1.02$)$ & $0.99(0.94$ to 1.04$)$ & $0.98(0.94$ to 1.02$)$ & $0.98(0.96$ to 1.05$)$ & $0.99(0.94$ to 1.03$)$ \\
\hline
\end{tabular}




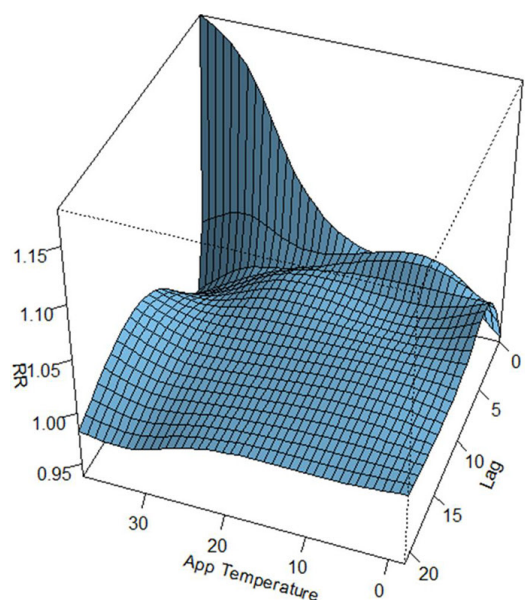

All-cases

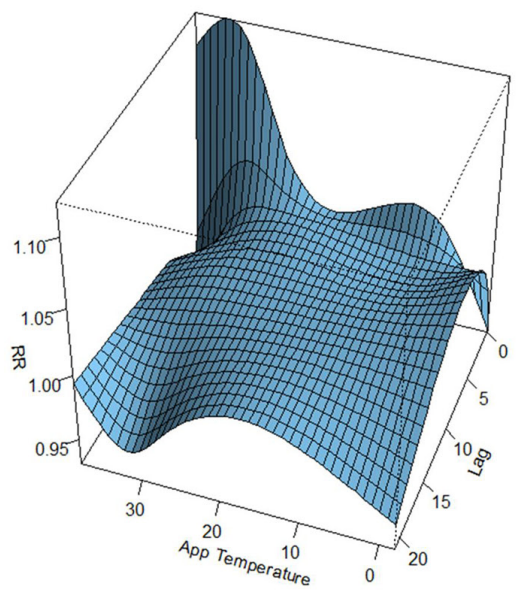

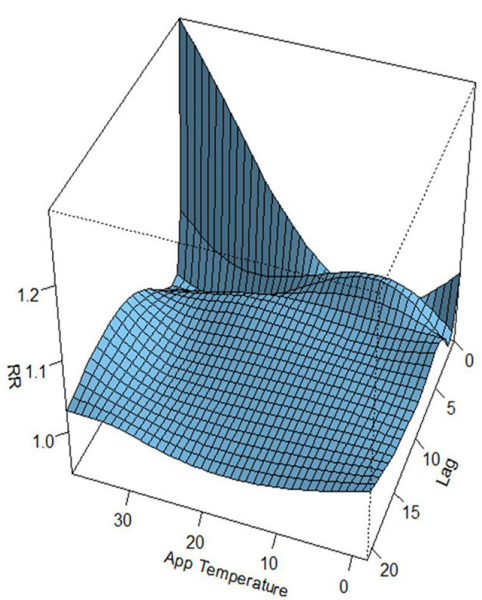

Females

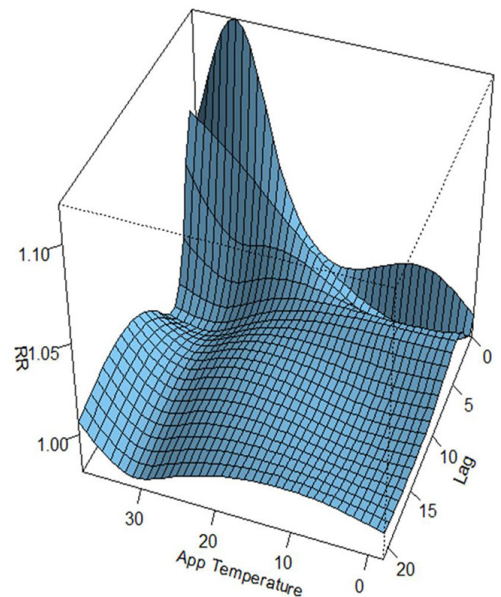

age $>=65$

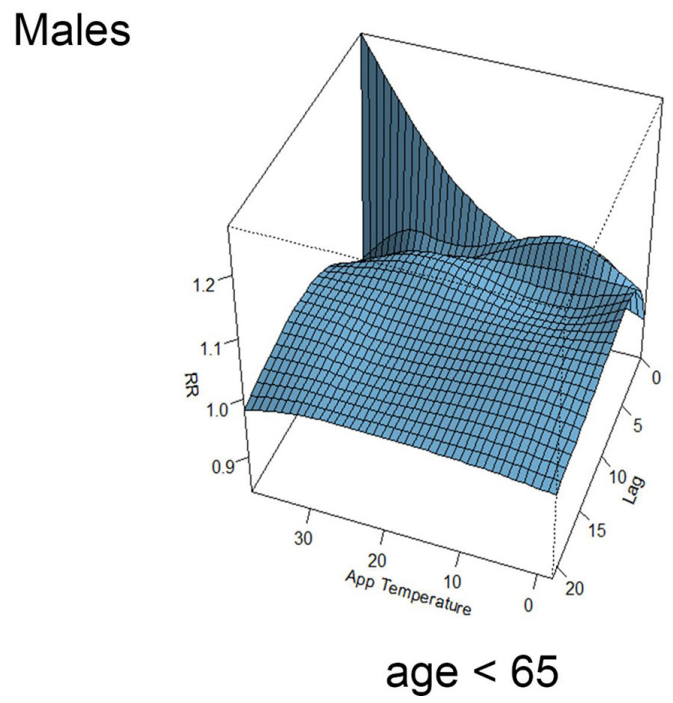

Figure 4 Relative risks of acute coronary syndrome admission by daily mean apparent temperature $\left({ }^{\circ} \mathrm{C}\right)$ and days of lag.

of the harmful effect of hot temperature on health, especially for vulnerable people, in the northern areas of Iran.

One of the strengths of this study is the application of apparent temperature instead of ambient temperature. This index combined heat and humidity, which is a composite index of human discomfort. It has long been recognised that the sensation of feeling hot or cold is not dependent on air temperature alone. During winter, humidity makes the temperature feel colder (we feel colder in a more humid climate). In summer, the humidity makes it feel hotter (we feel hotter in a more humid climate). Furthermore, we used DLNM here. The major advantage of this method is that it is flexible enough to simultaneously describe a non-linear exposure-response association and delayed effects or harvesting effect. ${ }^{31}$ 

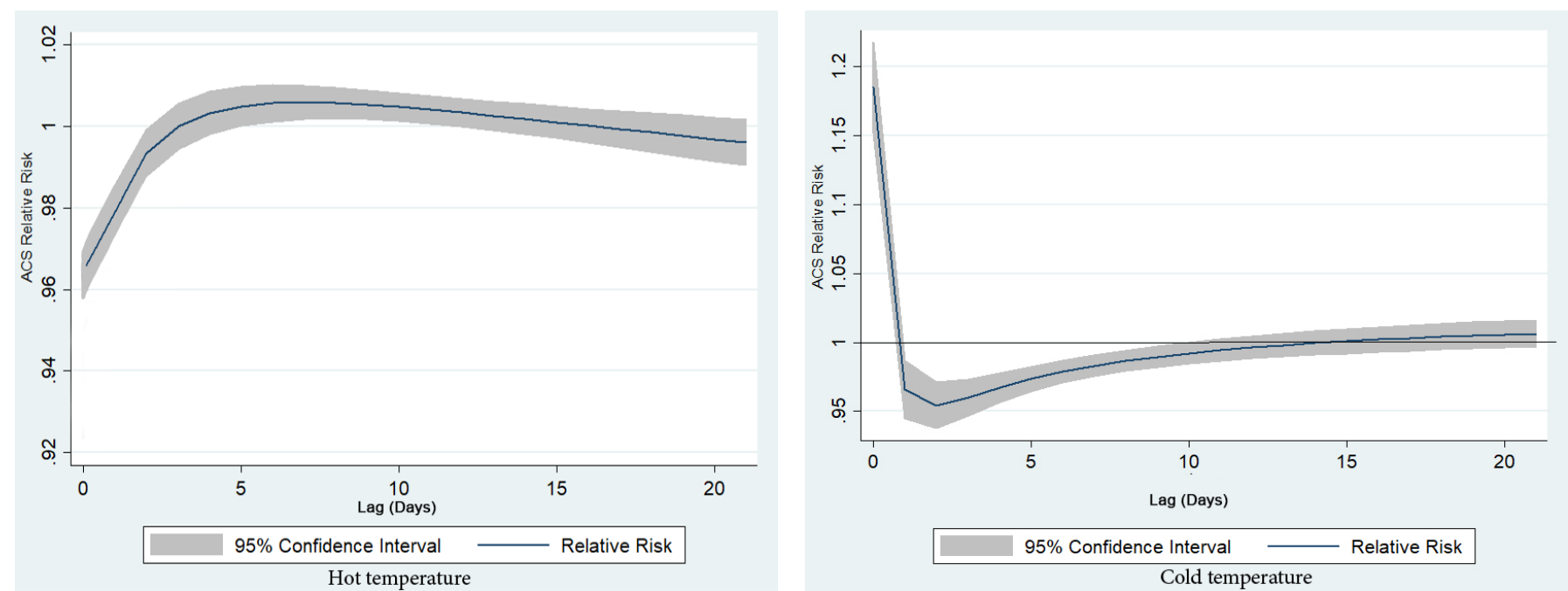

Figure 5 The effect of mean apparent temperature $\left({ }^{\circ} \mathrm{C}\right)$ on acute coronary syndrome admission along lag days.

There are some limitations in this study. We did not have data about air pollutants for the study period in Guilan province; therefore, we could not assess this confounder's effect in this study. Of course, Guilan province due to geographical location, such as proximity to the Caspian Sea and having appropriate wind and monsoon rain, has low pollutants levels.

Also in hospital-recorded data, there was no information on air conditioning use and the location where people spent most of their time. The lack of available data on the amount of fluid intake and the health status of subjects under study was another limitation of the present study.

\section{CONCLUSION}

We investigated the effect of apparent temperature on ACS admissions. A detrimental effect of high apparent temperature on ACS admissions was observed. We found stronger

\section{Key messages}

What is already known about this subject?

- Despite studies that examined the relationship between temperature and cardiovascular disease in some countries, especially developed countries, little has been done in lowincome and middle-income countries such as Iran.

- Also, most studies have examined cardiovascular disease in general, while in our study the relationship between temperature variability and acute coronary syndrome was specifically investigated.

\section{What does this study add?}

- The majority of ACS admission was caused by hot temperature. The strongest relationship between high apparent temperature and ACS was on the same day. The time-series plot of ACS admission and apparent temperature, showed the seasonal variationof exposure and response outcome in 10 years of study.

\section{How might this impact on clinical practice?}

- Adaptation strategies such as adequate hydration, as well as a well-established early warning system and emergency service seem to reduce the amount of ACS morbidity and mortality. high-temperature effect on ACS on the same day. These findings may help to better understand the relationship between temperature and morbidity in order to assist in developing effective public health intervention measures to prevent and reduce temperature-related mortality. Adaptation strategies such as using air conditioners in summer, adequate hydration, as well as a well-established early warning system and emergency service seem to reduce the amount of ACS morbidity and mortality.

Present affiliations The present affiliation of Mohammad Taghi Moghadamnia is: Department of Medical - Surgical Nursing, Guilan University of Medical Sciences, Guilan, Rasht, Iran and Ali Ardalan is: Harvard Humanitarian Initiative, Harvard University, Massachusetts, cambridge, United States.

Acknowledgements This study was part of a PhD thesis supported by Tehran University of Medical Sciences (TUMS).

Contributors All authors of the manuscript certify that they had the same contribution in writing the manuscript. MTM: developing and planning the research idea and preparing the final manuscript. AA: supervision and responsibility for the organisation. AM: responsibility for conducting a literature search. KN: conduct and reporting of the work. MSY: analysis of data and preparing the primary draft on outputs.

Funding The authors have not declared a specific grant for this research from any funding agency in the public, commercial or not-for-profit sectors.

Competing interests None declared.

Patient consent Not required.

Provenance and peer review Not commissioned; externally peer reviewed.

\section{REFERENCES}

1. Shonkoff SB. Climate change mitigation: climate, health, and equity implications of the visible and the hidden, 2012.

2. Moghadamnia MT, Ardalan A, Mesdaghinia A, et al. The effects of apparent temperature on cardiovascular mortality using a distributed lag nonlinear model analysis: 2005 to 2014. Asia Pac J Public Health 2018;30:361-8.

3. Wolf $K$, Schneider A, Breitner $S$, et al. Air temperature and the occurrence of myocardial infarction in Augsburg, Germany. Circulation 2009;120:735-42.

4. Ahmadnezhad E, Holakouie Naieni $K$, Ardalan A, et al. Excess mortality during heat waves, Tehran Iran: an ecological time-series study. J Res Health Sci 2013;13:24-31.

5. Wang YC, Lin YK. Association between temperature and emergency room visits for cardiorespiratory diseases, metabolic syndrome-related diseases, and accidents in metropolitan Taipei. PLoS One 2014;9:e99599.

6. Lin YK, Wang YC, Lin PL, et al. Relationships between cold-temperature indices and all causes and cardiopulmonary morbidity and mortality in a subtropical island. Sci Total Environ 2013:461-462:627-35.

7. Liang WM, Liu WP, Chou SY, et al. Ambient temperature and emergency room admissions for acute coronary syndrome in Taiwan. Int J Biometeorol 2008;52:223-9. 
8. Brunner LS, Smeltzer SCC, Bare BG, et al. Brunner \& Suddarth's textbook of medicalsurgical nursing: Lippincott Williams \& Wilkins. Lippincott: Williams \& Wilkins, 2010.

9. Åström DO, Forsberg B, Rocklöv J. Heat wave impact on morbidity and mortality in the elderly population: a review of recent studies. Maturitas 2011;69:99-105.

10. Hanzlíková H, Plavcová E, Kynčl J, et al. Contrasting patterns of hot spell effects on morbidity and mortality for cardiovascular diseases in the Czech Republic, 1994-2009. Int J Biometeorol 2015;59:1673-84.

11. Lin YK, Chang CK, Wang YC, et al. Acute and prolonged adverse effects of temperature on mortality from cardiovascular diseases. PLoS One 2013;8:e82678.

12. Ezekowitz JA, Bakal JA, Westerhout CM, et al. The relationship between meteorological conditions and index acute coronary events in a global clinical trial. Int J Cardiol 2013;168:2315-21.

13. Goggins WB, Chan EY, Yang CY. Weather, pollution, and acute myocardial infarction in Hong Kong and Taiwan. Int J Cardiol 2013;168:243-9.

14. Giang PN, Dung doV, Bao Giang K, et al. The effect of temperature on cardiovascular disease hospital admissions among elderly people in thai nguyen province, Vietnam. Glob Health Action 2014:7:23649.

15. Ebrahimi M, Kazemi-Bajestani SM, Ghayour-Mobarhan M, et al. Coronary artery disease and its risk factors status in iran: a review. Iran Red Crescent Med J 2011;13:610-23.

16. Zanobetti A, Schwartz J. Temperature and mortality in nine US cities. Epidemiology 2008; 19:563-70.

17. Stafoggia M, Forastiere F, Agostini D, et al. Vulnerability to heat-related mortality: a multicity, population-based, case-crossover analysis. Epidemiology 2006;17:315-23.

18. Yang J, Ou C-Q, Ding Y, et al. Daily temperature and mortality: a study of distributed lag non-linear effect and effect modification in Guangzhou. Environmental Health 2012;11:1.

19. Gasparrini A. Distributed lag linear and non-linear models in R: the package dlnm. J Stat Softw 2011;43:1.
20. Rocklöv J, Ebi K, Forsberg B. Mortality related to temperature and persistent extreme temperatures: a study of cause-specific and age-stratified mortality. Occup Environ Med 2011;68:531-6.

21. Anderson BG, Bell ML. Weather-related mortality: how heat, cold, and heat waves affect mortality in the United States. Epidemiology 2009;20:205.

22. Yang J, Ou CQ, Guo Y, et al. The burden of ambient temperature on years of life lost in Guangzhou, China. Sci Rep 2015;5:12250.

23. Guo Y, Punnasiri K, Tong S. Effects of temperature on mortality in Chiang Mai city, Thailand: a time series study. Environmental Health 2012;11:10.

24. Nastos PT, Giaouzaki KN, Kampanis NA, et al. Acute coronary syndromes related to bio-climate in a Mediterranean area. The case of lerapetra, Crete Island, Greece. Int J Environ Health Res 2013;23:76-90.

25. Wang $\mathrm{H}$, Kakehashi M, Matsumura M, et al. [Association between occurrence of acute myocardial infarction and meteorological factors]. J Cardiol 2007;49:31-40.

26. Yang J, Yin $\mathrm{P}$, Zhou $\mathrm{M}$, et al. Cardiovascular mortality risk attributable to ambient temperature in China. Heart 2015;101:1966-72.

27. Lee $S$, Lee E, Park MS, et al. Short-term effect of temperature on daily emergency visits for acute myocardial infarction with threshold temperatures. PLoS One 2014:9:e94070.

28. Yamaji K, Kohsaka S, Fujii K, et al. Daily weather and the occurrence of acute myocardial infarction. J Am Coll Cardiol 2014;63:A2.

29. Organization WH. Quantitative risk assessment of the effects of climate change on selected causes of death, 2030s and 2050s. World Health Organization, 2014.

30. Huang J, Wang J, Yu W. The lag effects and vulnerabilities of temperature effects on cardiovascular disease mortality in a subtropical climate zone in China. Int J Environ Res Public Health 2014;11:3982-94.

31. Lin $H$, Zhang $Y, X u Y$, et al. Temperature changes between neighboring days and mortality in summer: a distributed lag non-linear time series analysis. PLoS One 2013;8:e66403. 